Article

\title{
Fabrication of Superhydrophobic and UV-Resistant Silk Fabrics with Laundering Durability and Chemical Stabilities
}

\author{
Zihui Liang ${ }^{\dagger}$, Zezhu Zhou ${ }^{\dagger}$, Binghai Dong * and Shimin Wang * \\ Hubei Collaborative Innovation Center for Advanced Organic Chemical Materials, Ministry of Education Key \\ Laboratory for the Green Preparation and Application of Functional Materials, School of Materials Science and \\ Engineering, Hubei University, Wuhan 430062, China; liangzihui2008@163.com (Z.L.); \\ zhouzezhu@outlook.com (Z.Z.) \\ * Correspondence: dongbh2017@163.com (B.D.); shiminwang@126.com (S.W.) \\ + They contributed to the work equally.
}

Received: 13 March 2020; Accepted: 31 March 2020; Published: 3 April 2020

\begin{abstract}
To obtain a superhydrophobic surface, $\mathrm{SiO}_{2}$ nanoparticles are deposited on the surface of silk fabric (SF) by Plasma Enhanced Chemical Vapor Deposition (PECVD) to form a hierarchical roughness structure. In addition, a durable superhydrophobic $\mathrm{SiO}_{2} @$ silk fabric was further prepared by hexamethyldisilazane (HMDS) modification. Compared with bare silk, the surfaces of the $\mathrm{SiO}_{2} @$ silk fabric exhibit higher surface roughness and excellent superhydrophobic activity, with a contact angle (CA) of $\sim 152^{\circ}$. The excellent UV resistance of $\mathrm{SiO}_{2} @$ silk fabric was confirmed with high UV protection factor (UPF) values and a low UV transmittance. Moreover, both the laundering durability and chemical stability of the $\mathrm{SiO}_{2} @$ silk fabric were improved. Overall, this method is recognized as a promising approach to produce high-end fabric development. It can also guide the design of multifunctional fiber materials in the future.
\end{abstract}

Keywords: silk fabric; superhydrophobic coating; UV resistant; durability; HMDS

\section{Introduction}

Silk, a natural protein filament fiber, containing eighteen amino acids, has been widely used in textile manufacturing for a long time. Silk fiber has been regarded as "the queen of fibers" due to its many attractive characteristics, including its softness, comfort, high hygroscopicity, excellent mechanical strength, environmental stability, environmental friendliness, and renewability [1-5].

However, because of the abundant hydrophilic groups (hydroxyl, carboxyl, and amino) on the surface of silk fiber and fabric, it also brings some inherent defects, such as low thermal stability, high flammability, poor bacterial resistance, ease in being dirtied, and weak UV protection capability. This seriously hinders their extensive application for luxurious fashionable apparels [6,7]. Therefore, producing novel textiles, such as UV resistant and superhydrophobic silk fabrics, will help to meet the diversified needs of the consumer market.

Inspired by the lotus leaf, great efforts have been made to explore new superhydrophobic and UV resistant silk fibers/fabrics [8,9]. Ren et al. [10] reported a ZnO-PDMS coated fabric with good self-cleaning and UV resistance. Huang et al. [11] successfully constructed a robust superhydrophobic $\mathrm{TiO}_{2} @$ @fabric with a hydrothermal reaction method on a cotton fabric surface, which demonstrated good mechanical stability and exhibited self-cleaning and UV resistant properties. The surface of the anatase $\mathrm{TiO}_{2}$ sol was modified; then, the perfluorooctyl methacrylate (PFOMA) was used to prepare superhydrophobic fabric by thiolene click reaction, and this imparted the fabric with superhydrophobic and ultraviolet-blocking properties [12]. 
Although these studies have made some success in the field of preparing UV resistant silk fibers, the above methods, in many cases, are hardly able to form a stable coating structure, resulting in them being easily exfoliated from the surface of SF and, additionally, resulting in a deterioration of the superhydrophobic and anti-UV performances. Meanwhile, plenty of UV shielding agents can produce hydroxyl radicals and superoxide radicals under the UV light, owing to their high photocatalytic activities [13]. Given their strong oxidation properties, the radicals will damage the structure and composition of fibers/fabrics after they are further transmitted to the interface between UV shielding agents and fibers. PECVD is an effective conformal coating technology, which has the advantages of good uniformity, accurate thickness control, and strong adhesion. PECVD is a technology that uses glow discharge to ionize thin gas in a high frequency electric field to produce plasma. These ions are accelerated in the electric field to obtain energy, which can lead to the growth of thin film at low temperature [14]. $\mathrm{SiO}_{2}$ is the most favored inorganic material and has been widely applied because of its excellent chemical stability, mechanical strength, and high transparency [15]. In this work, $\mathrm{SiO}_{2}$ was coated onto silk fabric by PECVD, and a robust superhydrophobic $\mathrm{SiO}_{2} @$ silk fabric was further constructed by HMDS modification. The modified silk fabrics exhibited excellent superhydrophobicity and anti-UV properties. Moreover, the chemical and laundering durability of the finished silk fabrics will be discussed in detail. In general, this method is considered to be a promising way to produce high-end fabric. It shows promise for the design of multifunctional fiber materials in the future.

\section{Materials and Methods}

\subsection{Materials}

The white bare silk fabrics (SFs, plain weave, $63.3 \mathrm{~g} / \mathrm{m}^{2}$ ) used in this study were obtained from Tongxiang Home Textile, Ltd. (Zhejiang, China). $\mathrm{SiH}_{4}$ (Helium mixture, $10 \%$ of silane volume), $\mathrm{N}_{2}$ (99.999\% purity) and $\mathrm{N}_{2} \mathrm{O}$ were purchased from Wuhan Minghui Co., Ltd. (Wuhan, China). HMDS was directly obtained from Aladdin Industrial Co., Ltd. (Shanghai, China). Ethanol $\left(\mathrm{C}_{2} \mathrm{H}_{5} \mathrm{OH}\right)$ was bought from Sinopharm Chemical Reagent Co., Ltd. (Shanghai, China). The high-purity water used in the experiments was purified using a Milli-Q Plus 185 water purification system (Millipore, Bedford, MA) and had a resistivity of $10-16 \mathrm{M} \Omega \cdot \mathrm{cm}$ at $25^{\circ} \mathrm{C}$. Prior to PECVD, the silk fabrics and silk fibers were cleaned by the high-purity water and ethanol.

\subsection{Preparation of Superhydrophobic Silk Fabrics}

$\mathrm{SiO}_{2}$ nanofilms with plenty of active hydroxyl groups were prepared on the surface of silk fabrics by PECVD method. The reaction temperature was $150^{\circ} \mathrm{C}$, the deposition pressure was $90 \mathrm{~Pa}$, the RF power was $50 \mathrm{~W}$, and the deposition time was $5 \mathrm{~min}$. $\mathrm{SiH}_{4}$ (Helium mixture, 10\% of silane volume) and $\mathrm{N}_{2} \mathrm{O}\left(99.999 \%\right.$ purity) were used as reaction gas sources. The gas flow rate of $\mathrm{SiH}_{4}$ was $65 \mathrm{sccm}$ (sccm: standard milliliter/minute) and $\mathrm{N}_{2} \mathrm{O}$ was $450 \mathrm{sccm}$, respectively. High purity nitrogen $(99.999 \%)$ is scavenging gas, and its flow rate is controlled at no less than $13.4 \mathrm{sccm}$. Then, the $\mathrm{SiO}_{2} @$ silk fabric was added to the Teflon reactor with a $30 \mathrm{~mL}$ methanol solution and $7.5 \mathrm{~mL}$ HMDS. This was put into the oven at $80^{\circ} \mathrm{C}$ for $6 \mathrm{~h}$ and cooled at room temperature to form the superhydrophobic silk fabrics. Finally, the corresponding sample, with $\mathrm{SiO}_{2}$ coating of varied thickness, was modified by HMDS and marked as $\mathrm{SF}-\mathrm{nSiO}_{2}$, where $\mathrm{n}$ indicated the time of $\mathrm{SiO}_{2}$ deposition by PEVCD, respectively.

It can be seen from Figure 1a that the PECVD process for $\mathrm{SiO}_{2}$ deposition with $\mathrm{SiH}_{4}$ and $\mathrm{N}_{2} \mathrm{O}$ can be separated into a four-step reaction. When $\mathrm{SiH}_{4}$ and $\mathrm{N}_{2} \mathrm{O}$ are used to prepare $\mathrm{SiO}_{2}$ thin films by plasma enhanced chemical deposition, the initial reactant is $\left(\mathrm{SiH}_{3}\right)_{2} \mathrm{O}$, which is adsorbed on the substrate surface and reacts with oxygen atoms to form silicon dioxide with a stoichiometric ratio. Firstly, $\mathrm{N}_{2} \mathrm{O}$ is decomposed in the plasma to produce an oxygen atom or an oxygen radical, and the activated oxygen radical reacts with silane to form $\left(\mathrm{SiH}_{3}\right)_{2} \mathrm{O}$ or participates in the formation of oxide on the surface. Details are as follows: 


$$
\begin{gathered}
\mathrm{N}_{2} \mathrm{O}+\mathrm{X}^{*} \rightarrow \mathrm{NO}+\mathrm{N}^{*} ; \mathrm{NO}+\mathrm{X}^{*} \rightarrow \mathrm{N}^{*} ; \\
2 \mathrm{SiH}_{4}+\mathrm{O}^{*} \rightarrow\left(\mathrm{SiH}_{3}\right)_{2} \mathrm{O}+\mathrm{H}_{2} ;\left(\mathrm{SiH}_{3}\right)_{2} \mathrm{O}+\mathrm{O}^{*} \rightarrow \mathrm{SiO}_{2}+2 \mathrm{H}_{2}+\mathrm{H}_{2} \mathrm{O} ;
\end{gathered}
$$

Figure $1 \mathrm{~b}$ shows the schematic illustration of the schematic process of the fabrication of superhydrophobic and UV resistant silk fabrics. The water droplet quickly spread and completely wetted the bare fabric with the $\mathrm{CA}$ of $0^{\circ}$, indicating that the silk fabric was superhydrophilic (left inset of Figure 1c). However, the CA increased to $152^{\circ}$ on the surface of $\mathrm{SF}^{\circ} 5 \mathrm{SiO}_{2}$ (right inset of Figure 1c), which showed excellent superhydrophobicity.
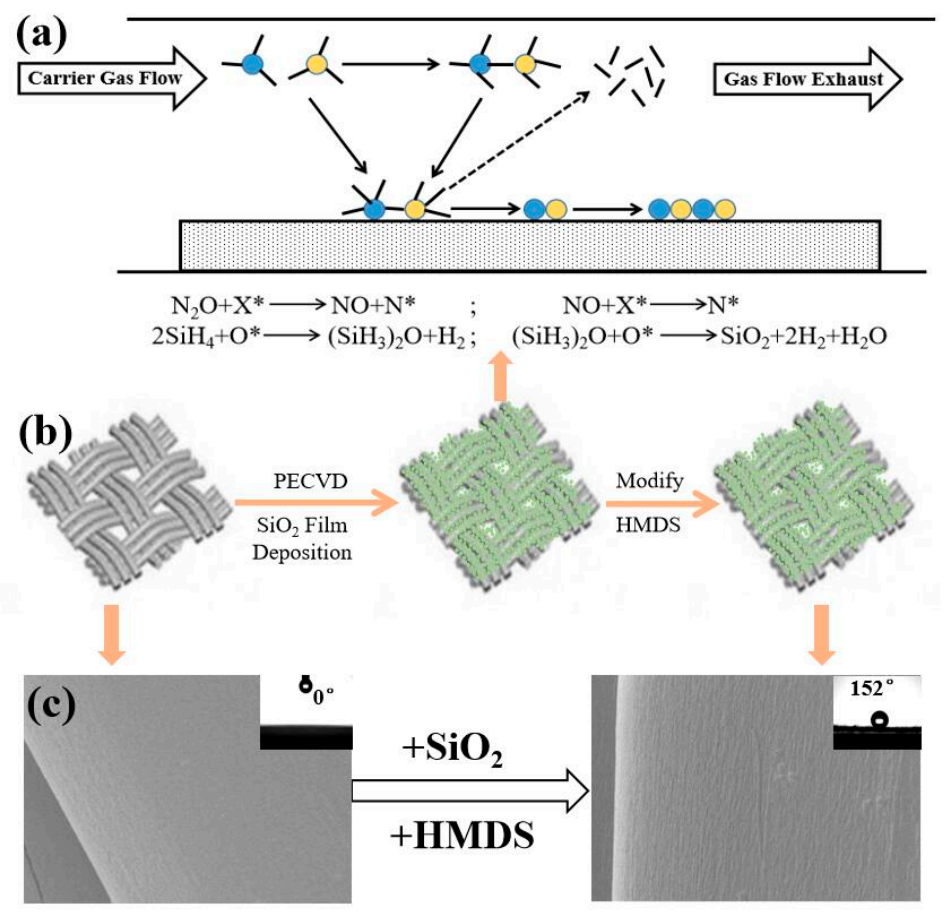

Figure 1. Schematic illustration (a) deposition $\mathrm{SiO}_{2}$ coating on silk fabric by PECVD. (b) the preparation of superhydrophobic and anti-UV silk fabrics; (c) The morphology and contact angles of bare silk and modified silk fabric.

\subsection{UV Radiation Treatment}

The UV resistance of the coating is the focus of this study. Therefore, we put the prepared silk fabric under the UV aging lamp for $30 \mathrm{~min}$. The power of the UV aging lamp is $40 \mathrm{~mW} / \mathrm{cm}^{2}$, the wavelength is $312 \mathrm{~nm}$, and the distance between the UV aging lamp tube and the silk fabric is fixed at $20 \mathrm{~cm}$.

\subsection{Characterization}

The surface morphology of the samples was measured by field emission scanning electron microscope (FE-SEM, JEM-6510LV) at an operating voltage of $5 \mathrm{kV}$. The elemental composition of samples was analyzed by an X-ray energy dispersive spectroscopy (EDS) detector (QX200, Bruker, Germany) attached to the FE-SEM. The contact angle system (KRUSS DSA100, Shanghai, China) was used to measure the static water contact angle of the super hydrophobic surface by using the seat drop method. Each layer was coated with 5 different points and about $5 \mu \mathrm{L}$ of deionized water was dripped. In order to characterize the surface roughness of the samples, the atomic force microscope (AFM, Park Systems XE-100, Suwon, Korea) was used to test them, and the relevant parameters were calculated by the equipment software. According to the GB/T14337-2008, the mechanical properties of 
the samples were tested along the radial direction on LLY-06E electronic single fiber strength tester (Laizhou Electronic Instrument Co., Ltd., Yantai, China). The test environment temperature is $20^{\circ} \mathrm{C}$, the relative humidity is $63 \%$, and the tensile rate is $10 \mathrm{~cm} / \mathrm{min}$. Measurements of all samples were repeated 15 times and an average value was taken.

\subsection{UV Resistance Evaluation}

According to the European standard EN13758-2:2003, the anti-UV performance of the sample should be measured with an HB902 anti-UV penetration and sun protection tester. The samples prepared should be measured by monochromatic or polychromatic ultraviolet (UV) radiation. The total spectral transmission rays in the samples should be collected, and the total spectral transmittance should be measured. The total UV protection coefficient (UPF value) should be calculated by the following equation [16,17]:

$$
\mathrm{UPF}=\frac{\sum_{280 \mathrm{~nm}}^{400 \mathrm{~nm}} \mathrm{E}_{\lambda} \times \mathrm{S}_{\lambda} \times \Delta \lambda}{\sum_{280 \mathrm{~nm}}^{400 \mathrm{~m}} \mathrm{E}_{\lambda} \times \mathrm{S}_{\lambda} \times \mathrm{T}_{\lambda} \times \Delta \lambda}
$$

where $E_{\lambda}$ denotes the solar spectral irradiance $\left(\mathrm{Wm}^{-2} \cdot \mathrm{nm}^{-1}\right), \mathrm{S}_{\lambda}$ denotes the relative erythema spectral effectiveness, $\Delta \lambda$ denotes the wavelength interval, and $\mathrm{T}_{\lambda}$ represents the averaged spectral transmittance of the silk fabric.

We have measured the color-related parameters (K/S value, $\left.L^{*}, a^{*}, b^{*}\right)$ of silk fabrics before and after ultraviolet irradiation with an X-Rite color i7 computer color measurement and matching system. At the same time, in order to further assess the UV resistance of different silk fabrics, we calculated the whiteness index (WI) and yellowness index (YI) by using the following formula through the color-related parameters [18,19]:

$$
\mathrm{WI}=100-\sqrt{(100-\mathrm{L} *)^{2}+(\mathrm{a} *)^{2}+(\mathrm{b} *)^{2}} ; \mathrm{YI}=\frac{142.86 \mathrm{~b} *}{\mathrm{~L} *}
$$

where $L^{*}$ denotes the brightness ranging from 0 (black) to 100 (white); positive value $\mathrm{a}^{*}$ denotes red, negative value $a^{*}$ denotes green, and $a^{*}$ varies from -100 (green) to 100 (red); positive value $b^{*}$ denotes yellowness, negative value $b^{*}$ denotes blueness, and $b^{*}$ varies from -100 (blue) to 100 (yellow), respectively.

\subsection{Chemistry Stability Evaluation and Laundering Durability Evaluation}

The silk fabrics were placed in $25 \mathrm{~mL}$ acid solution (hydrochloric acid)/ alkaline (sodium hydroxide) solution with different $\mathrm{pH}$ values and placed in a glass beaker at $20^{\circ} \mathrm{C}$ for $6 \mathrm{~h}$. According to AATCC 61-2009 method, accelerated washing durability tests of silk fabrics were carried out under condition 2A. The size of the stainless steel lever locking tank is $75 \times 125 \mathrm{~mm}$ (total volume $500 \mathrm{~mL}$ ). The obtained silk fabrics were washed at $50^{\circ} \mathrm{C}$ and $40 \pm 2 \mathrm{rpm}$ in $150 \mathrm{~mL}$ AATCC standard WOB detergent $(0.15 \%, w / w)$ and 50 stainless steel balls. Under condition $2 \mathrm{~A}$, one laundering cycle is equivalent to 10 commercial or household laundering cycles.

\section{Results}

\subsection{Surface Morphology and Composition Analysis}

Figure 2a-d shows the FE-SEM images of SF and SF- $5 \mathrm{SiO}_{2}$. As shown in FE-SEM images, it can be seen that the surface of the bare silk fabric is very smooth (Figure 2a,b). In contrast, many dense cracks and a few particle clusters can be observed on the surface of SF-5SiO 2 (Figure 2c, d), which may be attributed to the aggregation of neighboring $\mathrm{SiO}_{2}$ nanoparticles. The absence of cracks indicates that the SFs are completely covered by $\mathrm{SiO}_{2}$ layers. The energy dispersive X-ray (EDX) analysis shows that there is a continuous, uniform and dense $\mathrm{SiO}_{2}$ coating on the surface of $\mathrm{SF}-5 \mathrm{SiO}_{2}$ (Figure 2e-h). Figure 2j-m shows that the arithmetic average roughness (Ra) measured was 118, 158, 125, and $121 \mathrm{~nm}$ 
for the SF-nSiO 2 subjected to 2.5, 5, 7.5, and 10 min PECVD deposition, respectively. However, the $\mathrm{Ra}$ of bare silk fabric was only $74 \mathrm{~nm}$ (Figure 2i), which indicated that the $\mathrm{SiO}_{2}$ coating prepared has a certain surface roughness. After the deposition of $\mathrm{SiO}_{2}$ coating, the surface roughness of silk fabric increases. However, Ra is not a monotonic function of the PECVD exposure time. It reaches a maximum at around $5 \mathrm{~min}$ before it decreases, since silica further fills some of the grooves (weaving) on the surface of the silk fabric.
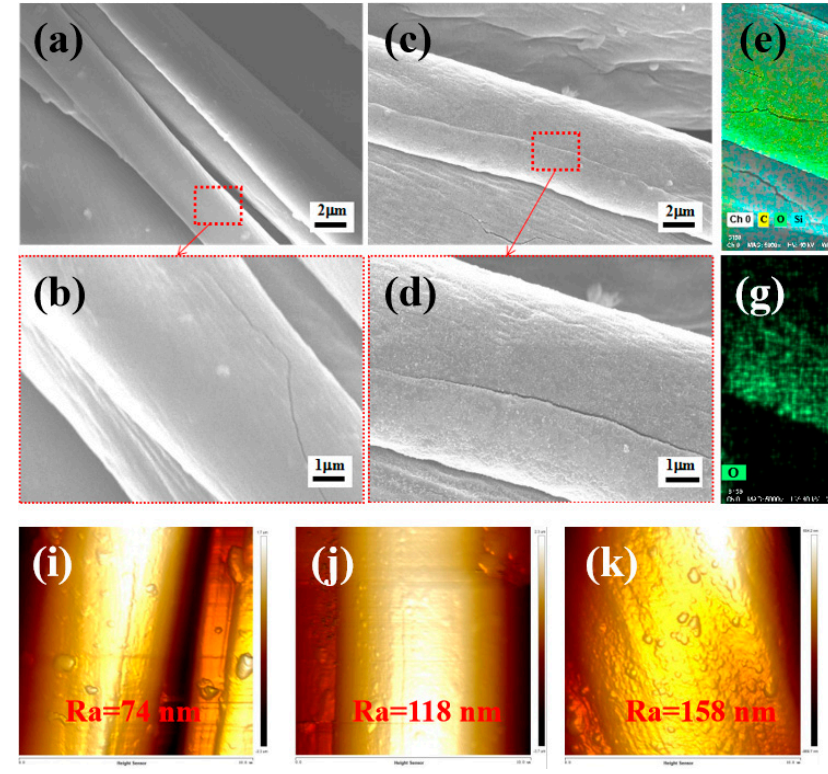

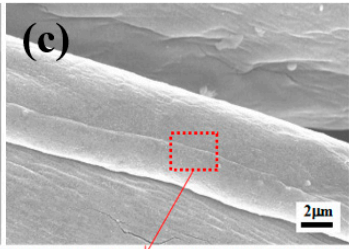

(d)
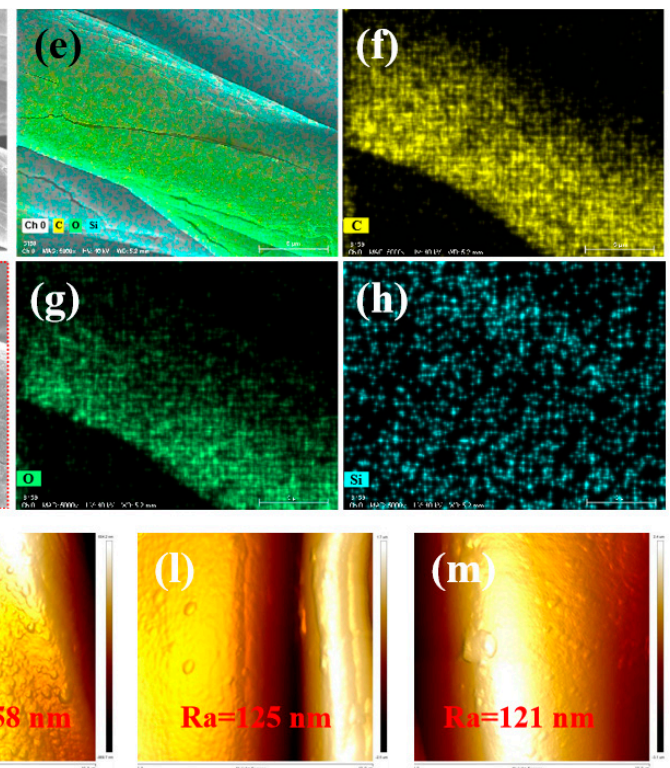

Figure 2. FE-SEM images of: $(\mathbf{a}, \mathbf{b})$ bare silk fabric, $(\mathbf{c}, \mathbf{d}) \mathrm{SF}-5 \mathrm{SiO}_{2} ;(\mathbf{e}-\mathbf{h})$ EDX mapping images of $\mathrm{SF}-5 \mathrm{SiO}_{2} ;(\mathbf{i}-\mathbf{m})$ AFM images of SF and SF-nSiO

\subsection{Surface Wettability Analysis}

The water contact angles of the $\mathrm{SF}-\mathrm{nSiO}_{2}$ were measured by using an OCA2.0 contact angle measurement system at $20^{\circ} \mathrm{C}$ with a $5 \mu \mathrm{L}$ water droplet. The contact angles were measured using the drop method at 5 different points on each sample. When water drops on the surface of silk fabric, it can be completely wetted; on the contrary, the surface of the modified silk fabric shows the superhydrophobicity with water contact angles (WCAs) of $152^{\circ}$ (as shown in Figure 3). Superhydrophobic surfaces are improved by increased surface roughness. This is completely consistent with the theory that was originally reported $[20,21]$. To evaluate the stability of the wetting properties after UV exposure, the contact angles of SF- $5 \mathrm{SiO}_{2}$, before and after UV light treatment for $30 \mathrm{~min}$, were measured and shown in Figure 4a,b. After UV irradiation, the wettability of the $\mathrm{SF}-5 \mathrm{SiO}_{2}$ was almost unchanged (Figure 4b). And it exhibits excellent surperhydrophobicity with WCAs of $150^{\circ}$, which indicates the wettability of the $\mathrm{SF}-5 \mathrm{SiO}_{2}$ has a strong tolerance to UV light. It is very important to endow the surface of silk fabric with the superhydrophobic property for stain resistance.

\subsection{UV Resistance Analysis}

Figure $5 \mathrm{a}, \mathrm{b}$ shows the UPF values and the UV transmittance curve for bare silk fabric and $\mathrm{SF}-\mathrm{nSiO}_{2}$. The UPFs for all samples were measured with 20 tests to find its average value. Compared with bare silk, the transmittance of the $\mathrm{SF}-\mathrm{nSiO} \mathrm{O}_{2}$ are lower, and the UPF values of the $\mathrm{SF}-\mathrm{nSiO}_{2}$ are higher, exhibiting excellent UV resistance properties. The results show that amorphous $\mathrm{SiO}_{2}$ plays an important role in the diffusion barrier layer and the passivation layer [15]. In addition, we measured the K/S values of bare silk and $\mathrm{SF}-\mathrm{nSiO} \mathrm{O}_{2}$ before and after UV light irradiation, as shown in Figure $5 \mathrm{c}$,d. Compared with bare silk, the $\mathrm{K} / \mathrm{S}$ values of $\mathrm{SF}-\mathrm{nSiO}_{2}$ slowly increased and were lower than that of bare silk. This indicates that $\mathrm{SF}-\mathrm{nSiO}_{2}$ has UV resistance. $\mathrm{SF}-\mathrm{nSiO}_{2}$ does not easily fade after $\mathrm{UV}$ irradiation. 


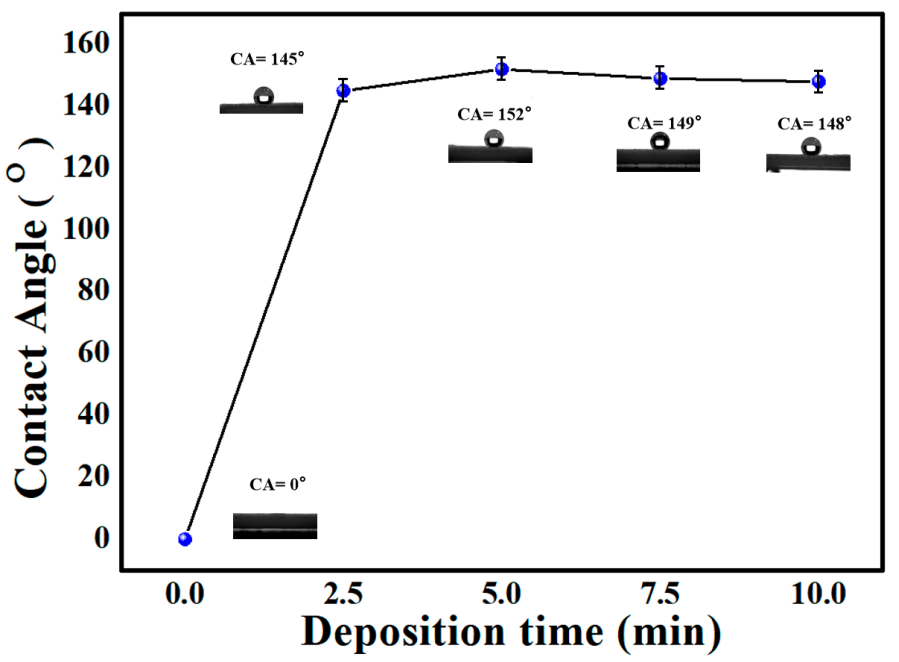

Figure 3. The contact angles of $\mathrm{SF}-\mathrm{nSiO}_{2}$ with different deposition times.

(a) (b)
$\mathrm{CA}=152^{\circ}$

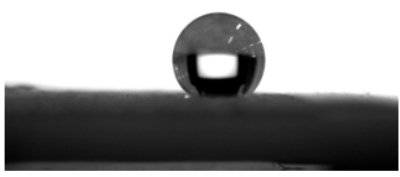

$\mathrm{CA}=150^{\circ}$

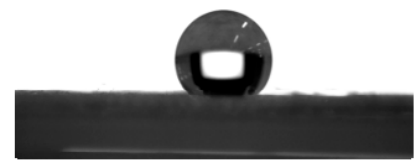

Figure 4. The contact angles of $\mathrm{SF}-5 \mathrm{SiO}_{2}$ : (a) before UV light treatment, and (b) after UV light treatment for $30 \mathrm{~min}$.
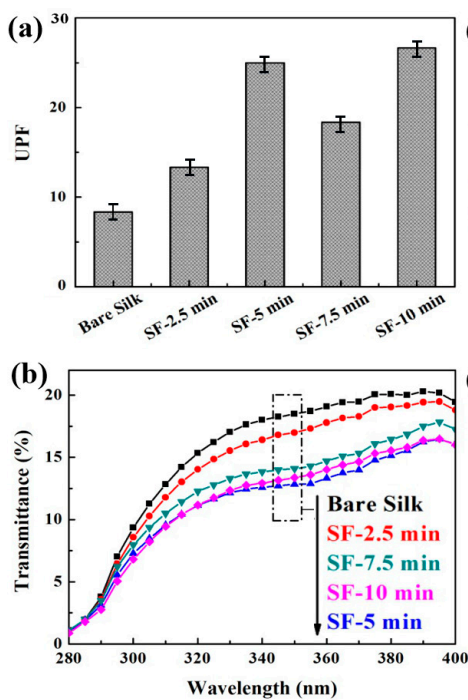

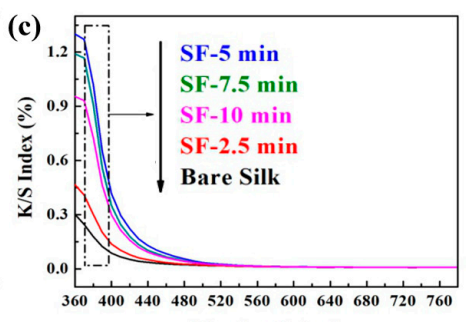

Wavelength (nm)

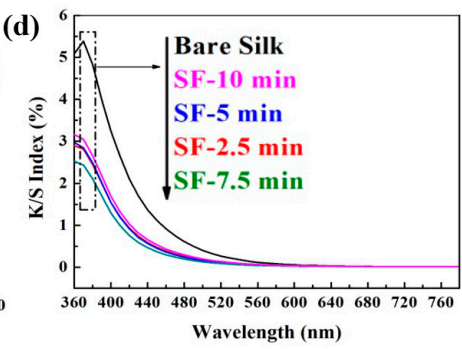

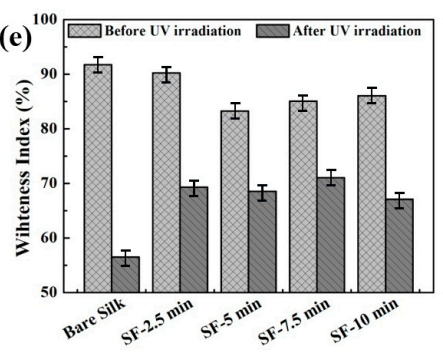

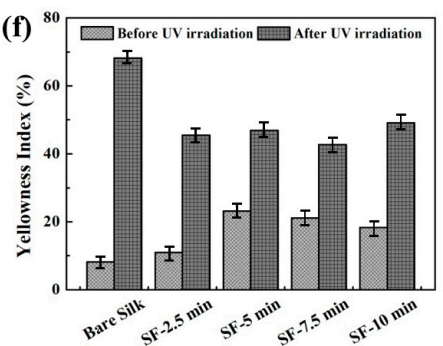

Figure 5. (a) UPF values of SF and SF-nSiO 2 ; (b) Ultraviolet transmission spectra of SF and $\mathrm{SF}-\mathrm{nSiO}_{2}$; Color strength indicator, $\mathrm{K} / \mathrm{S}$ value of $\mathrm{SF}$ and $\mathrm{SF}-5 \mathrm{SiO}_{2}$ : (c) without $\mathrm{UV}$ irradiation, (d) with UV irradiation for $30 \mathrm{~min}$; (e) whiteness index, (f) yellowness index of SF and $\mathrm{SF}-5 \mathrm{SiO}_{2}$ before and after UV irradiation for $30 \mathrm{~min}$.

To further compare the UV resistance of the different silk fabrics, the WI and YI were calculated. As Figure 5e,f shows, it is obvious that the WI and YI of the PECVD-coated silk fabrics have only slightly changed, compared with that of bare silk before the UV irradiation. This indicates that the deposition of $\mathrm{SiO}_{2}$ on the surface of silk fabric, through PECVD technology, will not affect the bulk silk 
fabric. After continuous exposure to UV light for $30 \mathrm{~min}$, the WI of bare silk significantly reduced from 93 to 56, while the YI increased from 8 to 68 , exhibiting yellowing. In this case, the main reason for the yellowing of silk fibers is that the amino acids with aromatic rings (such as tryptophan, tyrosine, and phenylalanine) in silk produce chromogenic conjugated systems under the action of UV light [22,23]. However, the WI and YI of the $\mathrm{SF}-5 \mathrm{SiO}_{2}$ did not change as much as that of bare silk under the same conditions, which demonstrates that $\mathrm{SiO}_{2}$ coating can decrease the yellowing of silk fabrics after UV treatment. This corresponds with the $\mathrm{K} / \mathrm{S}$ analysis above. In conclusion, the $\mathrm{SF}-\mathrm{nSiO}_{2}$ prepared has excellent UV resistance.

\subsection{The Mechanical Properties Analysis}

In addition, the mechanical properties of materials are important for evaluating their practical applications. It is necessary to improve the mechanical properties of silk fabrics as they are very easily damaged. Thus, we applied tensile tests to all samples before and after UV irradiation for $30 \mathrm{~min}$, and the average values for tensile stress and work fracture of all samples are given in detail in Figure 6a,b. To obtain accurate results, the values of tensile stress and work fracture of all samples were measured 10 times to obtain an average value. It is clearly seen that the values of tensile stress and work fracture of SF-nSiO ${ }_{2}$ are higher than that of bare silk. Moreover, the large increase in tensile stress and work fracture indicates that $\mathrm{SiO}_{2}$ can enhance the mechanical properties of silk fibers.
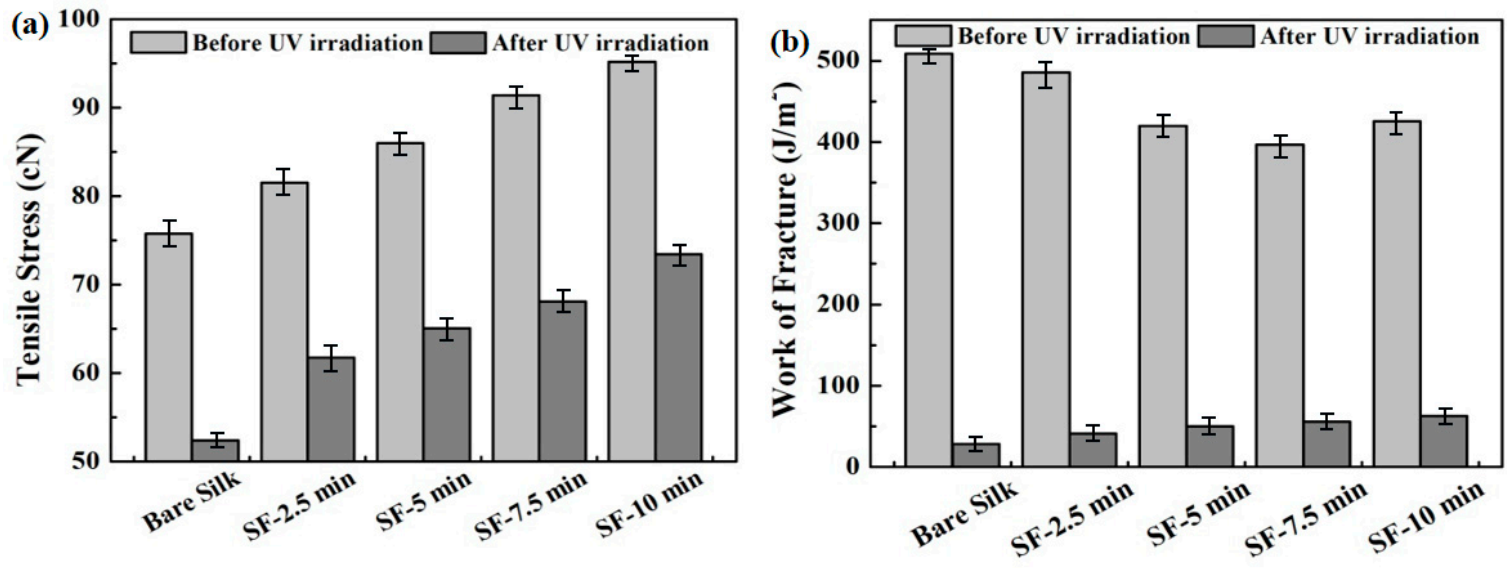

Figure 6. (a) Tensile tests; (b) Work fracture of SF and $\mathrm{SF}-5 \mathrm{SiO}_{2}$ before and after $\mathrm{UV}$ irradiation for $30 \mathrm{~min}$.

\subsection{Chemistry Stability and Laundering Durability Analysis}

For functional textiles, the contradiction between excellent functional characteristics and long-term durability and stability has always been a problem difficult to solve by scholars. Up to now, research progress has been unsatisfactory, especially for protective textiles with special functional coating. When these textiles, with special functional surfaces, contact with each other or with other substances outdoors, the functional coatings on their surfaces will wear to varying degrees due to sunlight, friction, or other external forces. They might also completely lose their functions, resulting in the failure of functional fabrics, which greatly limits the practical application and development of functional fabrics. The chemical stability and laundering durability are also key factors in determining the application of functionalized fabrics. Therefore, we have evaluated the chemical durability of $\mathrm{SF}-5 \mathrm{SiO}_{2}$ by soaking it in different $\mathrm{pH}$ solutions for $6 \mathrm{~h}$, and it maintained excellent superhydrophobic properties, which indicated that the finished silk fabric has excellent chemical stability (Figure 7a). In addition, the $\mathrm{SF}-5 \mathrm{SiO}_{2}$ was washed for different cycles according to the method of American Association of Textile Chemists and Colorists 61-2006 methods. The WCAs and WSAs of all samples were measured. After 30 cycles of repeated washing, the $\mathrm{SF}-5 \mathrm{SiO}_{2}$ remained superhydrophobic (Figure $7 \mathrm{~b}$ ), which might be due to the formation of a stable chemical bond between the $\mathrm{SiO}_{2}$ coating and the silk fabrics. 
(a)

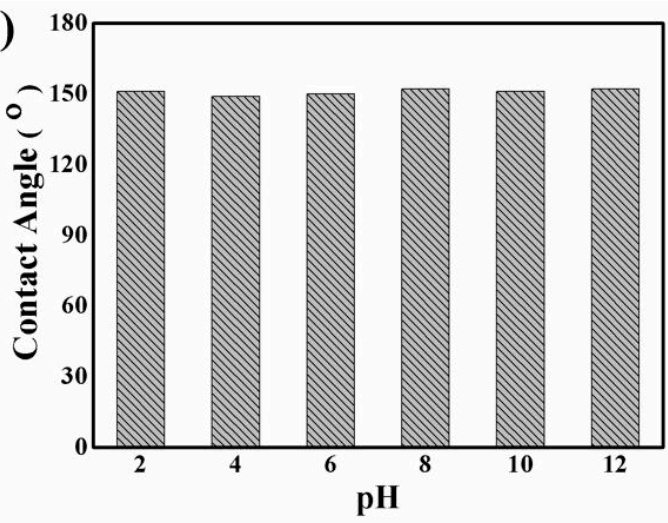

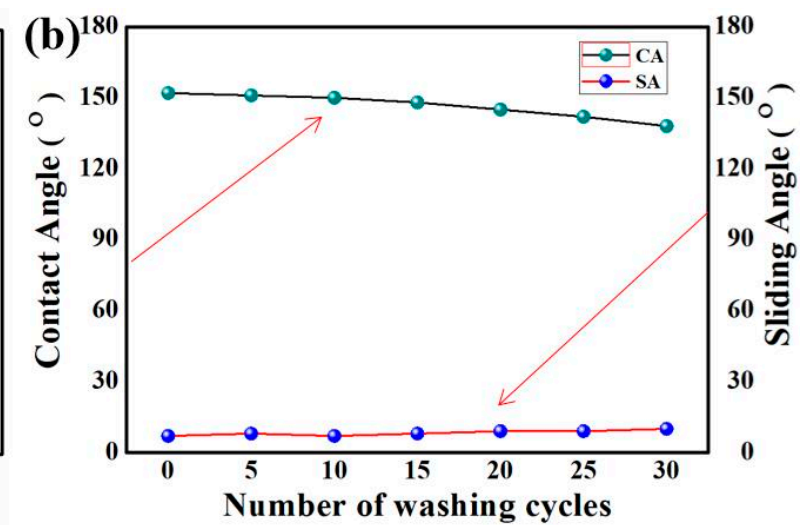

Number of washing cycles

Figure 7. (a) Chemical stability of SF-5SiO 2 ; (b) Laundering durability of $\mathrm{SF}-5 \mathrm{SiO}_{2}$.

\section{Conclusions}

In this study, a robust superhydrophobic and UV resistant silk fabric was successfully prepared. Compared with bare silk, the surface of the $\mathrm{SF}-5 \mathrm{SiO}_{2}$ exhibits higher surface roughness and excellent superhydrophobic activity with a contact angle of $\sim 152^{\circ}$. The excellent $\mathrm{UV}$ resistance of $\mathrm{SF}-\mathrm{nSiO}_{2}$ was confirmed with a high UPF value and a low transmittance, in the wavelength range of $280-400 \mathrm{~nm}$. Moreover, both the laundering durability and chemical stability of the $\mathrm{SiO}_{2} @$ silk fabric was improved. Based on these results, it can be concluded that PECVD is a promising modification method to endow silk fabrics with high UV protection and superhydrophobic properties. Overall, this method is recognized as a promising approach to producing high-end fabric. It can also guide the design of multifunctional fiber materials in the future.

Author Contributions: Conceptualization, B.D. and S.W.; methodology, Z.L.; software, Z.L.; validation, B.D. and S.W.; formal analysis, Z.L.; investigation, Z.Z.; resources, B.D.; data curation, Z.Z.; writing-original draft preparation, Z.L.; writing-review and editing, Z.L.; visualization, Z.Z.; supervision, B.D.; project administration, B.D.; funding acquisition, S.W. All authors have read and agreed to the published version of the manuscript.

Funding: This work was supported by the key projects of the Department of Hubei Provincial Science and Technology (2016AAA034) and the Natural Science Foundation of Hubei Province (2016CFB507). This work was also supported by the National Natural Science Foundation of China (51572072, 51603063, and 21402045).

Conflicts of Interest: The authors declare no conflicts of interest.

\section{References}

1. Kim, D.H.; Viventi, J.; Amsden, J.J.; Xiao, J.L.; Vigeland, L.; Kim, Y.S.; Blanco, J.A.; Panilaitis, B.; Frechette, E.S.; Contreras, D.; et al. Dissolvable films of silk fibroin for ultrathin conformal bio-integrated electronics. Nat. Mater. 2010, 9, 511-551. [CrossRef] [PubMed]

2. Shao, Z.; Vollrath, F. Surprising strength of silkworm silk. Nature 2002, 418, 741. [CrossRef] [PubMed]

3. Altman, G.H.; Diaz, F.; Jakuba, C.; Calbro, T.; Horan, R.L.; Chen, J.; Kaplan, D.L. Silk-based biomaterials. Biomaterials 2003, 24, 401-416. [CrossRef]

4. Rajkhowa, R.; Gupta, V.; Kothari, V. Tensile Stress-strain and Recovery Behavior of Indian Silk Fibers and Their Structural Dependence. J. Appl. Polym. Sci. 2000, 77, 2418-2429. [CrossRef]

5. Jin, H.J.; Kaplan, D.L. Mechanism of silk processing in insects and spiders. Nature 2003, 424, 1057-1061. [CrossRef]

6. Markus, H.; David, K.; Thomas, S. Spider Silk: From Soluble Protein to Extraordinary Fiber. Angew. Chem. Int. Ed. 2009, 48, 3584-3596.

7. Yang, H.Y.; Yu, Z.W.; Li, K.; Jiang, L.; Liu, X.; Deng, B.; Chen, F.X.; Xu, W.L. Facile and Effective Fabrication of Highly UV-Resistant Silk Fabrics with Excellent Laundering Durability and Thermal and Chemical Stabilities. ACS Appl. Mater. Interfaces 2019, 30, 27426-27434. [CrossRef]

8. Aslanidou, D.; Karapanagiotis, I. Superhydrophobic, superoleophobic and antimicrobial coatings for the protection of silk textiles. Coatings 2018, 8, 101. [CrossRef] 
9. Huang, J.J.; Yang, Y.Y.; Yang, L.; Bu, Y.M.; Xia, T.; Gu, S.J.; Yang, H.J.; Ye, D.Z.; Xu, W.L. Fabrication of multifunctional silk fabrics via one step in-situ synthesis of ZnO. Mater. Lett. 2019, 237, 149-151. [CrossRef]

10. Ren, G.N.; Song, Y.M.; Li, X.M.; Wang, B.; Zhu, X. A simple way to an ultra-robust superhydrophobic fabric with mechanical stability, UV durability, and UV shielding property. J. Colloid Interface Sci. 2018, 522, 57-62. [CrossRef]

11. Huang, J.Y.; Li, S.H.; Ge, M.Z.; Wang, N.Z.; Xing, L.N.; Chen, G.Q. Robust superhydrophobic TiO $@_{2} @ f a b r i c s$ for UV shielding, self-cleaning and oil-water separation. J. Mater. Chem. A 2015, 3, 2825-2832. [CrossRef]

12. Jiang, C.; Liu, W.; Yang, M.; Liu, C.; He, S.; Xie, Y.; Wang, Z. Robust multifunctional superhydrophobic fabric with UV induced reversible wettability, photocatalytic self-cleaning property, and oil-water separation via thiol-ene click chemistry. Appl. Surf. Sci. 2019, 463, 34-44. [CrossRef]

13. Yang, H.; Wang, Y.; Liu, K.; Liu, X.; Chen, F.; Xu, W. Facile fabrication of ultraviolet-protective silk fabrics via atomic layer deposition of $\mathrm{TiO} 2$ with subsequent polyvinylsilsesquioxane modification. Text. Res. J. 2019, 89, 3529-3538. [CrossRef]

14. Pai, P.G.; Chao, S.S.; Takagi, Y. Infrared spectroscopic study of SiOx films produced by plasma enhanced chemical vapor deposition. J. Vac. Sci. Technol. A 1986, 4, 689-694. [CrossRef]

15. Signorini, C.; Nobili, A.; Siligardi, C. Sustainable mineral coating of alkali-resistant glass fibres in textile-reinforced mortar composites for structural purposes. J. Compos. Mater. 2019, 53, 4203-4213. [CrossRef]

16. Xiao, X.F.; Liu, X.; Chen, F.X.; Fang, D.; Zhang, C.H.; Xia, L.J.; Xu, W.L. Highly anti-UV properties of silk fiber with uniform and conformal nanoscale $\mathrm{TiO} 2$ coatings via atomic layer deposition. ACS Appl. Mater. Interfaces 2015, 38, 21326-21333. [CrossRef]

17. Lavelli, V.; Pagliarini, E.; Ambrosoli, R. Physicochemical, Microbial, and Sensory Parameters as Indices to Evaluate the Quality of Minimally-processed Carrots. Postharvest Biol. Technol. 2006, 40, 34-40. [CrossRef]

18. Gao, Y.; Gereige, I.; El Labban, A.; Cha, D.; Isimjan, T.T.; Beaujuge, P.M. Highly transparent and UV-resistant superhydrophobic $\mathrm{SiO}_{2}$-coated $\mathrm{ZnO}$ nanorod arrays. ACS Appl. Mater. Interfaces 2014, 6, 2219-2223. [CrossRef]

19. Khanzadi, M.; Jafari, S.M.; Mirzaei, H. Physical and Mechanical Properties in Biodegradable Films of Whey Protein Concentrate-pullulan by Application of Beeswax. Carbohyd. Polym. 2015, 118, 24-29. [CrossRef]

20. Kubiak, K.J.; Wilson, M.C.T.; Mathia, T.G.; Carval, P. Wettability versus roughness of engineering surfaces. Wear 2011, 271, 523-528. [CrossRef]

21. Nakae, H.; Yoshida, M.; Yokota, M. Effects of roughness pitch of surfaces on their wettability. J. Mater. Sci. 2005, 40, 2287-2293. [CrossRef]

22. Chen, F.X.; Yang, H.Y.; Liu, X.; Chen, D.; Xiao, X.F.; Liu, K.; Li, J.; Cheng, F.; Dong, B.H.; Zhou, Y.; et al. Facile Fabrication of Multifunctional Hybrid Silk Fabrics with Controllable Surface Wettability and Laundering Durability. ACS Appl. Mater. Interfaces 2016, 8, 5653-5660. [CrossRef] [PubMed]

23. Wang, S.; Zhang, Y. Preparation of the Silk Fabric with Ultraviolet Protection and Yellowing Resistance Using $\mathrm{TiO}_{2} / \mathrm{La}$ (III) Composite Nanoparticles. Fibers Polym. 2014, 15, 1129-1136. [CrossRef]

(C) 2020 by the authors. Licensee MDPI, Basel, Switzerland. This article is an open access article distributed under the terms and conditions of the Creative Commons Attribution (CC BY) license (http://creativecommons.org/licenses/by/4.0/). 